\title{
Research on Quality Culture Construction of Engineering Projects
}

\author{
Peidong Sun \\ Tianjin University of Commerce \\ Tianjin, China 300134
}

\begin{abstract}
The formulation of the strategy of a country with high quality indicates the determination of Chinese industrial structure upgrading and product quality improvement and its scope covers all walks of life. As a part of the concept of a quality-strength strategy, quality culture must have a pivotal position in the whole process, but it is less involved in the current research. Based on the quality culture, this paper explores the improvement of engineering project construction efficiency in order to provide reference for enterprise application.
\end{abstract}

Keywords-quality culture; quality management; engineering projects

\section{INTRODUCTION}

While the construction of engineering projects in China has made rapid progress, the problems in project management cannot be ignored. Many factors such as huge investment, complicated technology, numerous participating units, and open environment have led to the unsatisfactory management performance of some large-scale projects. The quality is not up to expectations, the construction period is prolonged, and investment overruns occur from time to time. These problems arise from both human factors and management methods. How to solve related problems and avoid recurrence of problems, thus improving the quality and efficiency of project construction? Western management scholars believe that a superior corporate culture can effectively improve corporate performance by influencing the perceptions and behaviors of its employees, and the construction of a company's own culture is a new management method. After studying the existing literature, it is found that the majority of scholars pay more attention to the system level of quality management, while the concept of quality management is more contemptuous, and there is very little research on quality culture. The theory comes from practice and serves the practice. On the cognitive level, culture and institution should be placed in the same important position. According to their own national conditions and the specific needs of enterprises, they should deeply understand the quality culture, build a real and effective quality assurance system, and upgrade the project including quality and efficiency.

\section{RELATED CONCEPTS}

Quality culture is a part of organizational culture. It originated from TQM thinking and is indispensable in the construction of TQM system. Similarly, the construction of the project is also based on the TQM system. Looking at the existing literature on engineering quality and engineering culture, it can be found that scholars regard TQM as an important measure to improve the quality of the project. Based on this, this paper believes that the shaping and dissemination of quality culture is the key to the successful implementation of continuous improvement of engineering quality.

Quality management entered the stage of total quality management in the 1990s. TQM is an organization that is quality-focused and based on full participation, with the goal of achieving long-term success management through customer satisfaction and the benefits of all members of the organization and the society. The three core features of TQM are full participation, full process and comprehensive quality management. TQM includes four dimensions of structure, technology, people, and management drivers. Structure and technology are the hardware of TQM, and the people and management facilitators are TQM software.

This paper defines the quality culture of engineering as: a unique value judgment and thinking mode, behavior rules, rules and regulations and explicit forms formed in the practice of large-scale engineering, recognized and accepted by the members of the organization. And quality culture focuses on customer needs, emphasizes teamwork, and each member is committed to the quality of the project and is proud of working hard and teamwork to continually improve the quality of products and services. The enthusiasm and initiative of quality culture to mobilize engineering personnel is the key to improving the quality of work and ultimately improving the quality of the project. In addition, the quality of the project is ultimately determined by the quality and cultural behavior of all members.

\section{A. Project}

The project construction project is a concrete project expressed in physical form, which aims to form fixed assets. In China, engineering construction projects include capital construction projects (new capacity expansion projects such as new construction and expansion) and renovation and 
renovation projects (projects with the main purpose of improving technology, increasing product variety, improving quality, managing three wastes, labor safety, and conserving resources).

The construction of a project is different from the general management activities, and it has the following characteristics:

- Complexity. The project construction time span is long, the scope is wide, and the process is complicated. Internal and external links are difficult to run. Project management requires a coordinated team of all parties, requiring all personnel to comprehensively use a variety of subject knowledge including professional technology, economics, law, etc., work in unison, and solve problems in the construction process of the project at any time.

- Creativity. The project has a one-off feature and there are no two identical engineering projects. Even very similar projects have differences or differences in terms of time, location, materials, equipment, personnel, natural conditions, and other external environments. In the process of project decisionmaking and implementation, the project manager must proceed from the actual situation, combine the specific conditions of the project, and deal with and solve the actual problems of the project according to local conditions.

- Professionalism. Engineering project management needs to optimize the allocation and rational use of funds, personnel, materials, equipment and other resources. It is professional and technical, and requires specialized institutions and professional personnel for professional management.

The characteristics of the construction of the project determine that the formation and guarantee of its quality culture is different from the general management activities.

\section{B. Quality Culture}

Quality culture is not only a part of the enterprise quality management system, but also an important factor guiding and promoting the upgrading of enterprise quality management, and it runs through the whole activities of the enterprise. The quality assurance system is a set of management methods and methods used by enterprises to improve themselves. The operation is based on the quality plan and is controlled according to the management steps of the PDCA cycle theory to improve the assurance level. The quality assurance system depends on the quality objectives and must be improved according to the actual situation. To build a quality assurance system based on quality culture, we must start from the source and carefully grasp all the links to ensure the effectiveness and vitality of the system.

The meaning of "quality culture" refers to the material basis, technical knowledge, management thoughts, behavior patterns, which are gradually formed by the group or the nation in the quality practice activities based on the industrialization process since the modern times and the specific national culture, legal system and ethics and other factors and their sums." Quality is the life of an enterprise, and excellent corporate quality culture plays a vital role in the development and rise and fall of the enterprise. Construct a corporate quality culture that is consistent with corporate culture, thus establishing a quality brand strategy for the company and realizing long-term and stable development of the company.

It is generally believed that quality culture consists of four levels: material, behavior, system and morality. The material level is the basic level of quality culture. The behavioral level of quality culture is based on its material level. The material level is the carrier of behavior level. The institutional level of culture includes: standardization and normative system, reward system and legal system; the moral aspect of quality culture is not only the core content and the highest realm of quality culture, but also the ultimate goal of quality culture construction. Its performance is the organization's proactive respect and maintenancehe value orientation and spiritual pursuit of customer sovereignty. The moral level involves the following four group value orientations, namely respecting customer sovereignty; proactively maintaining the authority of social quality culture pursuing social benefits and perfectionism of behavioral outcomes; and treating economic resources in a continuous and lasting perspective, advocating social concept of sustainable development. These four levels form the quality culture pyramid in order from low to high.

The intersection of corporate culture and quality culture constitutes the enterprise quality culture. It is the unique quality culture that is applied to the enterprise in the process of quality management practice. It has the same products, processes and related systems as well as profound impact.

High-quality products are the basic guarantee for all enterprises to be recognized and developed. Only by relying on products can we gain more trust and business channels, so that enterprises can continue to grow and develop. For the construction of engineering projects, quality culture is not only the requirements for product quality, but also the quality of service and management, as well as the environmental quality and management quality that enterprises face. The construction of the project strengthens the construction of quality culture, which has the following advantages:

- It helps to improve the quality of the project. Strengthening the construction of quality culture can promote the interaction between quality and corporate culture, and make quality management become a part of corporate culture. In actual work, strengthen the promotion, guidance and education of quality culture, and have important education and guidance for the construction of engineering projects. The role of all employees in the construction project activities to promote the correct quality awareness, responsibility awareness and overall awareness, in strict accordance with the requirements and standards and practices to ensure the realization of quality objectives. Especially for the current fierce market environment, employees can consciously value and maintain product quality, 
achieve the guiding and binding force of quality culture, and thus improving the quality of enterprise products.

- Help to enhance market competitiveness. Under the economic development, China has entered a comprehensive reform period, and all enterprises are facing more challenges and opportunities in this environment. If the engineering construction unit wants to gain an advantage in the fierce market competition environment and win stable development, it must strengthen the construction of enterprise quality culture. Through internal publicity and education and guidance work, we will strengthen the quality awareness of all employees and establish a good corporate image and brand culture from the outside to provide guarantee for the long-term development of the company. The quality culture construction as part of the enterprise development strategy is conducive to reducing costs and increasing production efficiency, thereby enhancing the competitiveness of the enterprise market.

- Help to strengthen the management level of the enterprise. Modern project management is more economical, and management is infiltrated into all aspects of production and production, forming an independent and close management model between departments. The formation of quality culture has certain time characteristics. Under the continuous accumulation and precipitation, strengthening the construction of quality culture can achieve the penetration of quality management at all levels of enterprise management, and fully implement the improvement of management quality, product quality and service quality. Strengthening the construction of quality culture will help strengthen the management level of engineering projects and promote the sustainable development of construction units.

1) Customer-focused: Focusing on customers is the basic principle of quality management. The sustainable development of business activities is inseparable from customers. The customer is the recipient of the products and services provided by the company, the unit and the project. "Organization depends on customers" is the starting point and destination of ISO9000. "Customer-focused" is a driving force behind the development of contemporary society, and it is also a symbol of material and spiritual civilization. For enterprises, customers are the foundation of the existence of enterprises. Regardless of the nature of the enterprise, it is the manufacturing, service, and even schools. The value of its existence is to provide products or services to customers. Therefore, companies must regard customers as the focus of daily production, activities, and work, understand, identify and determine the current and future needs of customers, and establish quality objectives to form their own corporate quality culture. The construction of the project must also focus on the customer and implement it throughout the project construction activities.
2) QC team: the QC group is a small group based on quality management that people spontaneously form. It is an effective form to attract employees to participate in quality management. It should include leaders, technicians, and management personnel, and should focus on absorbing production and service. The front line staff participated. QC group activities are an effective way to promote corporate quality and cultural level and even corporate management. In the quality assurance system, QC team members should pay close attention to whether the enterprise quality standards are in line with the needs of enterprises, whether the enterprise quality assessment system is reasonable and effective, and whether the enterprise quality results meet the expected goals, and based on the actual situation, timely find problems and make reasonable suggestions. Alfazi Ahmed and Yves Van Nuran believe that an indispensable part of corporate quality culture is to create a work environment that promotes teamwork, growth and fairness. From this perspective, the QC team complements the quality culture. The $\mathrm{QC}$ team provides a stable environment for quality improvement, and the quality culture promotes the continuous improvement of the environment.

During the construction of the project, the QC team should also be established, and the project team members should be widely absorbed to ensure that all employees from the top to the bottom, all aspects of the supervision and control of quality activities, so as to better ensure the project The formation and improvement of construction quality culture, and promote the quality and efficiency of construction projects.

\section{Framework}

The construction project construction activities must be carried out under the conditions permitted by national laws and regulations. The quality of project construction should be based on national standards. This is the premise for constructing the quality assurance system of the project. In order to help enterprises better implement quality management practices, establish a quality management system, and ensure the high-quality operation of production and operation activities, the state has issued a series of relevant ISO series standards, covering all industries, each industry should meet their respective At the same time, in order to encourage enterprises to continuously improve product quality, national and local governments and related industries have established relevant quality awards to encourage an industry to make outstanding contributions in quality in a certain period of time. Enterprises and enterprises should aim at these awards and set their own quality objectives. 

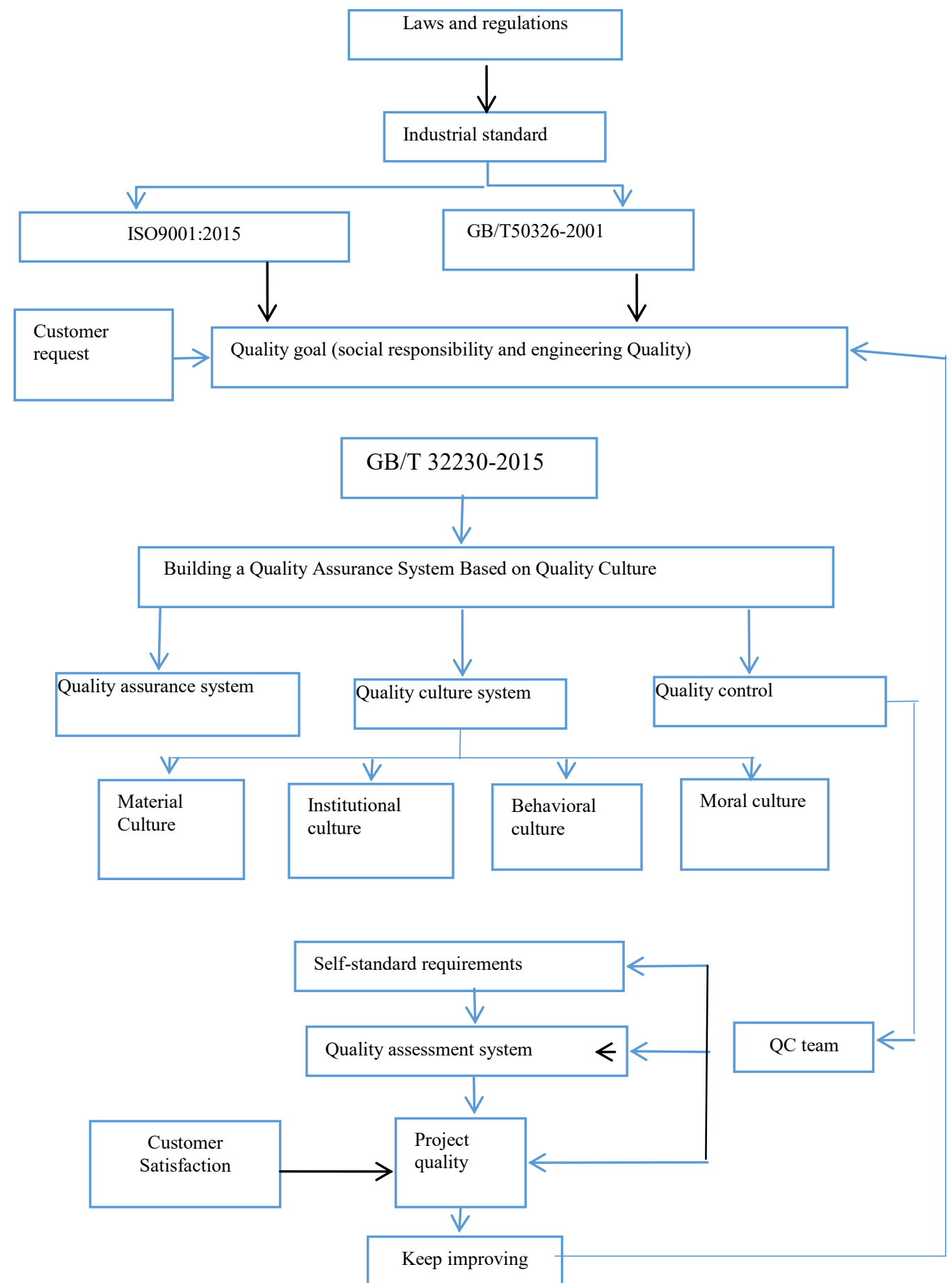

Fig. 1. Construction path diagram of quality assurance system based on quality culture.

As shown in "Fig. 1", the company's quality objectives are based on customer needs and related industry regulations, relevant industry national standards, ISO9000 standards. This ensures that the quality objectives of the project construction unit are reasonable and complete quality objectives based on national requirements and customer needs. The quality objectives of the construction of the project are reasonable, and the quality assurance system is effective and can contribute to the improvement of the quality of the enterprise. GB/T 32230-2015 "Guidelines for the Construction of Enterprise Quality Culture" has identified seven principles of quality culture: leadership, participation, systemic, integration, uniqueness, process approach, and effectiveness. And established a framework for quality culture construction, standardized the company's awareness and improvement of quality culture. Under the idea of TQM, the relevant theories and methods of quality management are based on the PDCA cycle for practical 
activities. The quality culture construction framework and the quality culture-based quality assurance system are all based on the method of cycle improvement. Therefore, after the engineering construction unit has developed its own quality standards and evaluation system, it should be based on customer satisfaction and test the quality results. If problems are found, they should be improved. In this process, the QC team should pay close attention and give reasonable advice.

ISO9001 is one of the core standards of a quality management system included in the ISO9000 family of standards. The ISO 9000 family standard is a concept proposed by the International Organization for Standardization (ISO) in 1994 and refers to "an international standard established by ISO/Tc 176 (International Organization for Standardization Quality Management and Quality Assurance Technical Committee).GB/T50326-2001 is the construction project management specification.GB/T $32230-2015$ is a guide to the construction of corporate quality culture. Based on these three system files, we can better grasp the specific details of the construction activities. And this paper builds a path for exploring the quality assurance system of engineering projects based on quality culture.

\section{CONCLUSION}

The main points and innovations of this paper are:

Combining the construction of quality assurance system with the construction of quality culture, the quality assurance system of engineering project construction not only serves as a practical activity for developing productivity, but also forms a comprehensive and full-member ideological and cultural activity. In the current period, strengthening the construction of quality culture is not only a requirement for the completion of the times, but also a due contribution to the times. Based on the quality and culture construction quality assurance system, the concept of continuous innovation, quality assurance and improvement, and the full implementation of the quality management system ensure that the quality assurance system is constructed and implemented to unify the consciousness of quality stakeholders, sex, quality awareness, quality responsibility, quality attitude and quality ethics. On this basis, the project construction unit can continuously enrich the connotation and even extension of its own system culture, and can continuously improve the overall management level and comprehensive management quality of the organization.

\section{REFERENCES}

[1] Quality management capabilities of manufacturing industries in the Western.

[2] Sydney region[J]. International Journal of Quality \& Reliability Management, 2

[3] $018,35(6)$.

[4] Amir A. Ghaferi. Surgical Collaboratives for Quality Improvement[J]. Surgical Oncology Clinics of North America, 2018, 27 (4)
[5] Kevin Kane,Joanne Zaida Taylor. Integrating culture and management control: is it oil and water or salad dressing?[J]. Worldwide Hospitality and Tourism Themes, 2018, 10(3).

[6] Chau Thi Ngoc QUYEN,KOSHIJIMA Ichiro. Fundamental Study on Countermeasures for Overseas Construction Project Trouble[J]. Proceedings of International Association of P2M, 2017. Autum(0).

[7] J. Ferreiro-Cabello, E. Fraile-Garcia,E. Martinez-Camara, M. Perezde-la-Parte. Sensitivity analysis of Life Cycle Assessment to select reinforced concrete structures with one-way slabs[J]. Engineering Structures, 2017, 132 